\title{
Further Report on Bunyonyi Leprosy Colony, Kigezi, for 1933-4, with Statistics.
}

L. E. S. SH'ARP.

$7 \mathrm{HE}$ activities and scope of the anti-leprosy measures, undertaken by the colony, have made great progress during the last twelve months. This has been due to :-

1. Increasing numbers of admissions to the colony.

2. The greatly increased assistance given by the Government in grants and native labour.

3. The addition to our staff of Miss Forbes, who is a trained and experienced teacher, as well as Miss Martin, who has been acting Matron of the hospital during Miss Langley's absence.

There were two hundred and twenty-two fresh admissions during the last twelve months, thus increasing the total from 300 to 522 by April, 1934. This increase has proportionately increased the work of the Hospital, in the way of injections, dressings and general treatment; in addition to the management of hygienic measures necessary in administering and caring for so large a number of semiinvalid persons. During 1933-34 the Kigezi administration built 35 grass huts for newcomers, and this year have undertaken to supply the labour for building 35 more permanent and hygienic huts to replace old grass ones. These huts are being constructed of brick and thatched with papyrus. Last September, a hurricane tore a part of the roof from the hospital; this has been repaired and the Hospital generally renovated. The extra land, reclaimed from the wild pig, granted to the colony last year for purpose of cultivation, has been much appreciated, and half of it is already under excellent crops. This year, provision for pasturage for flocks and herds, on the neighbouring island of Bushara, has made the inmates even more contented. To make provision for the future for firewood, etc., some 50,000 eucalyptus trees have been planted.

On September 5th, 1933, His Excellency and Lady Bourdillon visited the colony to open the new school buildings. There are now over 100 children in this school, under Miss Forbes and a staff of six teachers, half of whom, are inmates in the colony. The Government E.V. Syllabus is followed, for which purpose the school is divided into 
seven classes. Most satisfactory progress has been made both physically and mentally. Of 100 children, 33 have become arrested during the year, a most gratifying result. The need of a home for untainted children has been felt for some time, owing to the susceptibility of young children to infection from their parents. (We have a well developed case only six weeks old !) This has been provided through the generosity of a supporter of the Mission to Lepers, and the building is now completed, consisting of two dormitories, a nursery playroom, and the necessary service quarters. It has been built on an ideal site, on the top of a hill well above the regular village life of the colony. Here we have planned to admit all children under five not infected, and are getting them as early as possible. It is found that the chances of children becoming infected by their parents is very great. There are 34 babies under five in the colony already infected, and perhaps 26 under five still uninfected. So that $57 \%$ of children become infected before five years of age, and probably $\mathbf{7 5 \%}$ eventually, if not separated. The difficulties of getting the parents' consent is not inconsiderable, and tact and patience are needed.

Sixty visitors have inspected the colony during the year, including the following Government officials:- the Assistant Chief Secretary, the Director of Medical and Sanitary Services, the Assistant Director of Medical and Sanitary Services and the Provincial Commissioner. The colony has enjoyed the continued co-operation and assistance of the local Administration, which is doing much to further the purposes of the colony. These anti-leprosy measures would be made still further effective and permanent were some of the native chiefs more capable, and their influence more respected by the peasantry in parts of the district where there still remains a great deal of leprosy.

There is one matter which, if rectified, would have a most beneficial effect on the whole question of leprosy in this district. It will be noted from the statistical sheets as follows :-

1. That at least $60 \%$ of children of lepers become infected while they are little children. 16.

2. One-third of the population here are children under

3. That of these children $75 \%$ are in the category $\mathrm{Cl}$ and N1, i.e., early or mild cases.

4. That among $194 \mathrm{Cl}$ and $\mathrm{N} 1$ cases in the colony, $43 \%$ became arrested during the year. 
5. That of all arrested cases during 1933, i.e., $90,92 \%$ were $\mathrm{Cl}$ and $\mathrm{N} 1$ cases.

With these figures in mind, it is indeed a tragedy that parents are allowed to prevent their children from coming into the colony. Yet hundreds of such parents are preventing their children, who are early cases, from a very fair chance of recovery and good health for purely selfish reasons, such as the excuse so often heard, "I need them to fetch water for me, and to collect my firewood." The Regulation permitting infected adults to live among the healthy, infecting their neighbours and children, will, I suppose, not be altered at present. But could not a modification be introduced, to the effect that where infected children are found, their parents or guardians may not prevent their admission to a colony, which is efficiently run to the satisfaction of the Government? It would seem that the statistical evidence we possess justifies some such modifications; and general considerations of Infant and Child Welfare demand no less. Such a modification would also indirectly provide just that added incentive to infected parents to migrate to the colonies, which is so desirable and beneficial to all concerned.

This suggestion is earnestly commended to the Committee's support, with a view to being recommended for consideration to His Excellency the Governor.

Notes on Compiling of Statistics.

Classification.-The inmates for convenience have been divided into the following classes :-

1. $\mathrm{C} 1$ and $\mathrm{N} 1$ or a combination of both, which comprise all early cases and mild infections.

2. C2 and C3, all severe cutaneous infections.

3. N2 and N3, nerve cases of long standing or extensive nerve infection.

4. Mixed 2 and 3, severe cases, including heavy infection of both kinds.

Results of Treatment.-It is often very difficult to estimate with accuracy as to whether any particular case is improved or not, or again, arrested or not. Most of the early cases are negative microscopically, and every case is not susceptible to measuring of the lesions. The results have been arrived at as far as possible by measurement of lesions, and general health has also been brought into consideration. It is hoped that the large numbers observed in each type, and with each form of treatment will, however, outweigh any uncertainty which may have existed in estimating the result in a few of the cases. 
Extent of Treatment.-My statistics for last year were perhaps open to one criticism, in that I did not differentiate between those who had received many injections of, say, alepol, and so had been adequately influenced by the drug, and those cases which received few injections. I have, therefore, following the example of other workers as reported in the LEPROSY REVIEW, divided the results of treatment in each case into three categories:-

1. Cases treated with many injections.

2. Cases treated with few injections.

3. Cases treated without any specific injections.

In this way it would seem possible, not only to observe which cases did better on alepol, for example, or those without injections, but also whether increasing the number of injections would improve the aggregate results; and so a double check on the effect of any drug can be obtained. The cases are divided under types, and also under five different courses of treatment :-

1. Alepol.

2. Hydnocreol.

3. Brilliant Green.

4. Mixed courses of the above.

5. No specific injections.

Again, 1, 2, 3 and 4 are subdivided into many or few injections.

As will be seen from the types treated, a fair number of every type has been treated with each of all five courses, and the cases have not been specially selected in any way.

Total numbers in Colony, 25/4/34: 522.

Total under treatment 3 months and over, surveyed 1933-34: 396.

$$
\begin{array}{lrrlr}
\text { Died } \quad . . & 13=3 \% & \text { Improved } \quad 180=46 \% \\
\text { Worse } \ldots & 33=8 \% & \text { Arrested ... } & 90=23 \% \\
\text { Stationary } & 80=20 \% & &
\end{array}
$$

Ages and sexes of inmates (405):-

Infants $(1-4) \ldots \quad \ldots$ Males 12 Females 22

Ghildren $(5-15) \quad \ldots . \quad, \quad 58 \quad, \quad 37$

Young Adults $(16-30) \quad$ " $78 \quad$ " 47

Middle aged and old $(30-70)$ " $86 \quad$ " 65

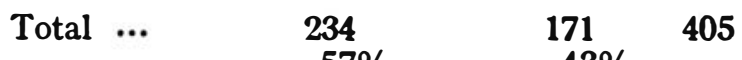

Types of Leprosy :-

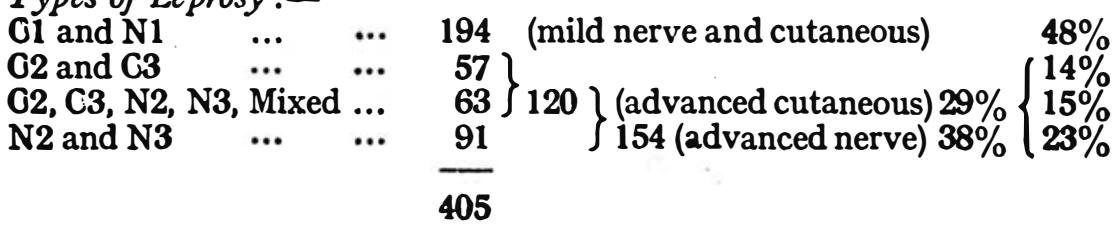

Totals.

$$
\begin{array}{r}
34=8 \% \\
95=24 \% \\
125=31 \% \\
151=37 \%
\end{array}
$$


Types Arrested:-

$$
\begin{aligned}
& \mathrm{N} 1 \text { and } \mathrm{Cl} \quad 83=92 \% \\
& \mathrm{~N} 2 \text { and N3 } \quad 6=7 \% \\
& \text { Mixed } \ldots .1=1 \% \\
& 90 \\
& \text { N1 and C1 } 194 \text { Mild cases } \\
& 83 \text { Arrested }=43 \%
\end{aligned}
$$

Total results of treatment with and without specific injections

(a) Total treated with many specific injections $\quad \ldots \quad \ldots$

Worse $\quad . .23=11 \% \quad$ Improved $98=49 \%$

Stationary $46=23 \% \quad$ Arrested ... $34=17 \%$

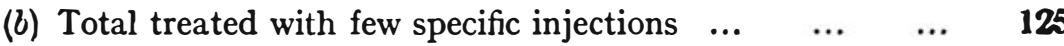

Worse $\ldots \quad 9=8 \% \quad$ Improved $56=45 \%$

Stationary $27=21 \% \quad$ Arrested ... $33=26 \%$

(c) Total treated without specific injections $\ldots \quad \ldots \quad \ldots$

Worse $\quad . . \quad 1=2 \% \quad$ Improved $26=46 \%$

Stationary $\quad 7=12 \% \quad$ Arrested ... $23=40 \%$

TREATEd on Alepol.-Results.

Treated on few injections alepol $(1-8)$ exclusively. Cases : 92. N1 and C2 cases: 42.

Results : Worse $\ldots 1=2 \%$ Improved $8=19 \%$

$$
\text { Stationary } 11=26 \% \text { Arrested } 22=53 \%
$$

N2 and N3 cases : 23.

Results : Worse $\ldots 2=9 \%$ Improved $17=74 \%$

$$
\text { Stationary } 3=13 \% \text { Arrested } 1=4 \%
$$

Treated on few injections alepol $(1-8)$ exclusively.

$\mathrm{C} 2$ and $\mathrm{C} 3$ cases: 15.

Results: Worse $3=20 \%$ Improved $7=47 \%$

$$
\text { Stationary } 5=33 \%
$$

Mixed N2 and N3, C2 and C3 cases : 12.

Results : Worse ... $2=17 \%$ Improved $7=58 \%$

$$
\text { Stationary } 2=17 \% \quad \text { Arrested } \quad 1=8 \%
$$

Treated on many injections alepol (8-30) exclusively. Cases 103. $\mathrm{N} 1$ and $\mathrm{C} 1$ cases : 42.

Results : Worse ... $2=5 \%$ Improved $13=31 \%$

$$
\text { Stationary } 17=40 \% \quad \text { Arrested } \quad 10=24 \%
$$

N2 and N3 cases : 26.

Results : Worse ... $3=11 \%$ Improved $14=54 \%$ Stationary $6=24 \%$ Arrested $3=11 \%$

$\mathrm{C} 2$ and $\mathrm{C} 3$ cases : 12.

Results : Worse ... $2=17 \%$ Improved $7=58 \%$ Stationary $3=25 \% \quad$ Arrested $\quad 0$ 
Mixed cases C2, N2, C3, N3 : 23.

Results : Worse ... $8=35 \% \quad$ Improved $12=52 \%$ Stationary $3=13 \%$ Arrested 0

Treated exclusively on few injections alepol : 92 .

Results: Worse $\ldots 8=9 \%$ Improved $39=42 \%$ Stationary $21=23 \%$ Arrested $24=26 \%$

Treated exclusively on many injections alepol : 103.

Results : Worse $15=15 \% \quad$ Improved $46-44 \%$ Stationary $29=28 \% \quad$ Arrested $\quad 13=13 \%$

Treated exclusively on alepol : 195 .

Results : Worse $23=11 \% \quad$ Improved $85=44 \%$ Stationary $50=26 \% \quad$ Arrested $37=19 \%$

Treated exclusively on few injections $(1-8)$ hydnocreol : 9.

Results: Worse ... 0 Improved $6=67 \%$ Stationary $1=11 \% \quad$ Arrested ... $2=22 \%$

Treated exclusively on many injections $(9-30)$ hydnocreol : 24.

Results : Worse $\ldots 1=4 \%$ Improved $17=71 \%$ Stationary $4=17 \%$ Arrested $2=8 \%$

Treated exclusively on hydnocreol : 33 .

Results : Worse $1=3 \% \quad$ Improved $23=70 \%$ Stationary $5=15 \% \quad$ Arrested $\quad 4=12 \%$

Treated exclusively on few injections $(1-8)$ Brilliant Green: 16.

Results : Worse $\ldots 0$ Improved $8=50 \%$ Stationary $2=13 \% \quad$ Arrested $6=37 \%$

Treated exclusively on many injections (9-30) Brilliant Green : 9.

Results : Worse $\ldots 1=11 \%$ Improved $4=45 \%$ Stationary $1=11 \%$ Arrested $3=33 \%$

Treated exclusively on Brilliant Green : 25.

Results : Worse $1=4 \% \quad$ Improved $12=48 \%$ Stationary $3=12 \% \quad$ Arrested $9=36 \%$

Treated on few mixed injections $(1-8)$. Total 8 .

$\begin{array}{lll}\text { Results: } & \text { Worse } \quad 1=12 \% & \text { Improved } 3=38 \% \\ \text { Stationary } 3=38 \% & \text { Arrested } \quad 1=12 \%\end{array}$

Treated on many mixed injections $(9-40)$. Total 65.

$\mathrm{Nl}$ and $\mathrm{Cl}$ cases : 24.

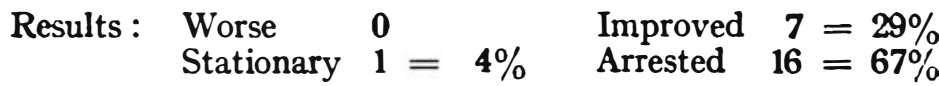

N2 and N3 cases: 16. Results : $\begin{array}{lll}\text { Worse } \ldots 1=6 \% & \text { Improved } & 9=56 \% \\ \text { Stationary } 6=38 \% & \text { Arrested } & 0\end{array}$

C2 and C3 cases: 15.

Results: Worse $3=20 \% \quad$ Improved $8=53 \%$ Stationary $4=27 \% \quad$ Arrested $\quad 0$ 
C2, N2, C3, N3 cases : 10.

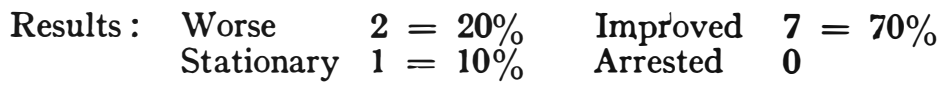

Total cases treated by mixed injections $(9-40): 65$.

Results : Worse .. $6=9 \% \quad$ Improved $31=48 \%$ Stationary $12=18 \% \quad$ Arrested $16=25 \%$

Treated without specific injections : 57.

N1, C1 cases: 46.

Results : Worse $0 \quad$ Improved $20=44 \%$ Stationary $4=8 \% \quad$ Arrested $22=48 \%$

N2, N3 cases : 4.

$\begin{array}{llll}\text { Results : } & \begin{array}{l}\text { Worse } \ldots \\ \text { Stationary }\end{array} & 0 & \text { Improved } 3=75 \% \\ \text { Arrested } 1=25 \%\end{array}$

C2, C3 cases : 2.

$\begin{array}{lllll}\text { Results : } & \begin{array}{l}\text { Worse } \ldots \\ \text { Stationary }\end{array} & 0 & \text { Improved } & 2=100 \% \\ \text { Arrested } & 0\end{array}$

C2, N2, C3, N3 cases: 5 .

Results: Worse $1=20 \% \quad$ Improved $1=20 \%$

Stationary $3=60 \%$ Arrested 0

Total treated without specific injections: 57.

Results: Worse $1=2 \% \quad$ Improved $26=46 \%$

Stationary $7=12 \%$. Arrested $23=40 \%$

Observations on Statistics.

1. The results of treatment in the Colony for 1933-34, taken as a whole, are quite as encouraging as last year. They show a low death-rate, and a large percentage of improvements and arrests.

2. The high percentage of children affected and the large number of arrests among them have already been commented on elsewhere in the report.

3. Forty-eight per cent. of all cases are $\mathrm{Cl}$ and $\mathrm{N} 1$, and of these $43 \%$ shew arrest.

4. In providing an adequate number of controls, as explained above, it is hoped that the statistics will be of greater value than uncontrolled figures.

5. Taking each treatment separately, it seems generally to apply that there is little to choose in efficacy between the drugs tested, and that comparative results suggest that the fewer the injections the more favourable the result.

I do not claim that this is actually the case, but it suggests that the value of these drugs has often been overestimated, and will in time be found to be limited to certain types of case.' 